Pathophysiology of Haemostasis and Thrombosis
Pathophysiol Haemost Thromb 2003;33:121-126

DOI: $10.1159 / 000077819$
Received: May 16, 2003

Accepted after revision: September 24, 2003

\title{
Influence of a Long-Term, High-Dose Volume Therapy with $6 \%$ Hydroxyethyl Starch 130/0.4 or Crystalloid Solution on Hemodynamics, Rheology and Hemostasis in Patients with Acute Ischemic Stroke
}

\author{
Results of a Randomized, Placebo-Controlled, Double-Blind Study \\ Ralph Woessnera Markus T. Grauera Hans-Jürgen Dieterich ${ }^{b}$ \\ Frank Bepperling ${ }^{c}$ Daniela Baus ${ }^{c}$ Timo Kahles $^{d}$ Sven Georgi ${ }^{d}$ \\ Oliver Bianchid Martin Morgenthalera Johannes Treiba \\ aDepartment of Neurology, Westpfalz Klinikum, University City of Kaiserslautern, Kaiserslautern, \\ bDepartment of Anaesthesiology, University of Tübingen, Tübingen, 'Department of Clinical Research, \\ Fresenius Kabi, Deutschland GmbH, Bad Homburg, dDepartment of Neurology, University of the Saarland, \\ Homburg/Saar, Germany
}

\section{Key Words}

Stroke $\cdot$ Hydroxyethyl starch $\cdot$ Cardiac output $\cdot$ Blood pressure

\begin{abstract}
Background: This study was performed to investigate the clinical effects of a 4-day volume therapy with a newly developed, $6 \%$ hydroxyethyl starch (HES) 130/0.4 versus crystalloid solution, with particular regard to systemic and cerebral hemodynamics, rheology and safety. Methods: In a randomized, double-blind study, 40 patients suffering from an acute ischemic stroke received either $6 \%$ HES $130 / 0.4$ or crystalloid solution as continuous infusion over 4 days with a total dose of 6.5 liters. Efficacy parameters studied included hemodynamics (cardiac output, blood pressure, flow velocity with transcranial Doppler) and rheology (hematocrit and plasma viscosity). Safety parameters examined included laboratory, hemostaseology (including factor VIII) and an adverse event questionnaire (including pruritus). Results: In both groups, a small, but not significant increase in
\end{abstract}

cardiac output was observed. There were no significant changes regarding the remaining efficacy or safety parameters, except for the well-known increase in serum alpha-amylase through the infusion of HES. Conclusion: In our study with patients suffering from acute ischemic stroke, continuous infusion ( $1 \mathrm{ml} / \mathrm{min}$ ) of HES $130 / 0.4$ or crystalloid solution did not differ regarding safety or hemodynamic efficacy.

Copyright @ 2003 S. Karger AG, Basel

\section{Introduction}

During recent decades, the issue of whether colloid or crystalloid solutions are preferable for volume replacement and volume therapy has been the subject of ongoing discussion $[1,2]$. In patients with acute ischemic stroke, intravenous administration of volume is a generally accepted therapy regimen for the treatment hypovolemia and dehydration, which are often present $[2,3]$. In general, crystalloid solutions are used for this. Colloidal solutions are used in the volume therapy of ischemic stroke in

\begin{tabular}{ll}
\hline KARGER & ( 2003 S. Karger AG, Basel \\
1424-8832/03/0333-0121\$19.50/0 \\
$\begin{array}{l}\text { Fax +4161306 12 34 } \\
\begin{array}{l}\text { E-Mail karger@karger.ch } \\
\text { www.karger.com }\end{array}\end{array}$ & $\begin{array}{l}\text { Accessible online at: } \\
\text { www.karger.com/pht }\end{array}$
\end{tabular}

Priv.-Doz. Dr. med. Johannes Treib, MD

Department of Neurology

Westpfalz-Klinikum GmbH, University Teaching Hospital

DE-67655 Kaiserslautern (Germany)

Tel. +49631 203 1792, Fax +49 631203 1977, E-Mail jtreib@westpfalz-klinikum.de 
particular in German-speaking countries [3]. Earlier studies showed that isovolemic hemodilution results in no clinical improvement $[4,5]$. The goal of hypervolemic volume therapy with hydroxyethyl starch (HES) is to affect hemodynamics and rheology more favorably than through the administration of crystalloid solution alone [6-10]. In addition to that, there is some new evidence that a vascular anti-inflammatory action may underline the beneficial effects of HES [11].

In recent years, rapid progress has been made in the field of volume therapy as far as HES preparations are concerned. Moreover, the availability of certain HES solutions differs considerably between countries [12]. Initially, HESs were developed for the military, where they were used as a one-time infusion to compensate for a blood loss for as long as possible until the next medical station could be reached. For this reason, HES with a high initial molecular weight of $450 \mathrm{kD}$ and a high molar substitution of 0.7 was used, which is difficult to metabolize and subsequently difficult to eliminate. After repeated administration, a variety of problems occurred, particularly with coagulation and storage [13].

In the first attempt to reduce these problems, the initial molecular weight was lowered to $200 \mathrm{kD}$, resulting in HES $200 / 0.62$. Soon it was realized that the decisive point was the molar substitution. HES preparations developed later (HES 200/0.5 and HES 70/0.5) solved this problem through a lower molar substitution of 0.5 , which allowed for much easier renal elimination [14]. In further studies, we showed that the breakdown rate of HES also depends on the $\mathrm{C} 2 / \mathrm{C} 6$ hydroxyethylation ratio. The higher this ratio, the slower the breakdown. However, the effect of the $\mathrm{C} 2 / \mathrm{C} 6$ ratio is smaller than the effect of the molar substitution [15]. The newest HES preparation (HES 130/ 0.4 ), which was recently approved in most European countries, has a molar substitution of only 0.4 . With such a low molar substitution, it is expected that the molecules are cleaved rapidly enzymatically, resulting in a fast elimination and a short duration of the volume effect. To avoid this, the distribution curve of the molecular weight was narrowed for HES 130/0.4 and a higher C2/C6 ratio was selected.

The goal of the present study was to examine the hemodynamic and rheological effects of a continuous volume therapy through a high-dose therapy with HES in comparison with crystalloid solution in patients suffering from acute stroke. Although this is a frequently used therapy, so far, no data are available regarding the effect on hemodynamics, with particular focus on cardiac output and cerebral blood flow velocity [16]. In addition, high-dose, long- term volume therapy of cerebral perfusion disorders with HES offers a suitable model to study the therapeutic safety of this colloidal plasma substitute, including the effects on coagulation and the occurrence of side effects. This is the case because large volumes are administered to patients without relevant accompanying diseases, blood loss or trauma.

\section{Patients and Methods}

\section{Ethics}

The study was approved by the independent ethics committee of the Physician Chamber of the State of Saarland, Germany. The study was conducted in accordance with the ethical principles of the Declaration of Helsinki as modified in Somerset West 1996, international conference on harmonization (ICH), good clinical practice (GCP) and German national regulatory requirements. All patients gave their signed written informed consent to participate in the study.

\section{Patients}

In a prospective, double-blind, placebo-controlled study, 40 patients suffering from acute ischemic stroke were randomized into two groups, receiving either HES 130/0.4 or crystalloid solution (electrolyte). Exclusion criteria were intracranial hemorrhage, aphasia, known allergy to HES, cardiac insufficiency (NYHA III-IV), known coagulation disorders, recent trauma or blood loss and renal insufficiency. Patients who had received thrombolytic medication, e.g. rtPA or streptokinase, oral anticoagulants or full-dose heparin, were not included in the study. Prior administration of acetylsalicylic acid and concomitant administration of low-dose heparin to prevent deep vein thrombosis were not exclusion criteria.

Patients underwent a thorough medical examination before inclusion in the study as well as follow-up exams on day 5 and the day of discharge. After 90 days, a follow-up was carried out through a telephone interview. All patients were treated in the intensive stroke unit of the Department of Neurology of the University of Homburg/ Saar, Germany.

Study patients received a loading dose of $500 \mathrm{ml}$ of $6 \%$ HES 130/ 0.4 (Voluven ${ }^{\circledR}$, Fresenius Kabi Deutschland $\mathrm{GmbH}$ ) or crystalloid solution (Jonosteril ${ }^{\circledR}$, Fresenius Kabi) within $1 \mathrm{~h}$. Then, 1,500 ml were infused over $24 \mathrm{~h}$ on days $1-4$, for a total volume of $6,500 \mathrm{ml}$ of HES or crystalloid solution.

\section{Parameters}

The parameters investigated in this study at different time points are shown in table 1.

Primary Efficacy Variable. The primary variable of this study was the cardiac output and its changes from baseline until $24 \mathrm{~h}$, measured noninvasively by the bioimpedance method [16].

Secondary Efficacy Variables. Hemodynamics (cardiac output, blood pressure, heart rate) were monitored continuously in the intensive stroke unit during the study period. Cerebral perfusion was measured by flow velocity in the middle cerebral artery using transcranial Doppler (TCD). Hemostaseology (platelets, prothrombin time, activated partial thromboplastin time, fibronectin, factor VIII:C, von Willebrand factor antigen, von Willebrand ristocetin cofactor) and routine laboratory parameters (hemoglobin, leukocytes, glucose, cre- 
Table 1. Study flowchart

\begin{tabular}{|c|c|c|c|c|c|c|c|c|c|c|}
\hline & $\begin{array}{l}0 \mathrm{~h} \\
\text { (baseline) }\end{array}$ & $1 \mathrm{~h} \pm 15 \mathrm{~min}$ & $6 \pm 1 \mathrm{~h}$ & $24 \pm 2 \mathrm{~h}$ & $48 \pm 6 \mathrm{~h}$ & $72 \pm 6 \mathrm{~h}$ & $96 \pm 6 \mathrm{~h}$ & $5 \pm 1$ days & $\begin{array}{l}\text { Day of } \\
\text { discharge }\end{array}$ & $90 \pm 9$ days \\
\hline Written informed consent & $\mathrm{X}$ & & & & & & & & & \\
\hline Inclusion/exclusion criteria & $\mathrm{X}$ & & & & & & & & & \\
\hline $\begin{array}{l}\text { Demographic data, medical history, } \\
\text { concomitant diseases }\end{array}$ & $\mathrm{X}$ & & & & & & & & & \\
\hline Concomitant medication & $\mathrm{X}$ & $\mathrm{X}$ & $\mathrm{X}$ & $\mathrm{X}$ & $\mathrm{X}$ & $\mathrm{X}$ & $\mathrm{X}$ & $\mathrm{X}$ & $\mathrm{X}$ & \\
\hline Physical examination & $\mathrm{X}$ & & & & & & & & $\mathrm{X}$ & \\
\hline CT scan of the head, 12-lead ECG & $\mathrm{X}$ & & & & & & & & & \\
\hline Cardiac output & $\mathrm{X}$ & $\mathrm{X}$ & $\mathrm{X}$ & $\mathrm{X}$ & $\mathrm{X}$ & $\mathrm{X}$ & $\mathrm{X}$ & & & \\
\hline Cerebral perfusion & $\mathrm{X}$ & $\mathrm{X}$ & $\mathrm{X}$ & $\mathrm{X}$ & $\mathrm{X}$ & $\mathrm{X}$ & $\mathrm{X}$ & & & \\
\hline Blood pressure, heart rate & $\mathrm{X}$ & $\mathrm{X}$ & $\mathrm{X}$ & $\mathrm{X}$ & $\mathrm{X}$ & $\mathrm{X}$ & $\mathrm{X}$ & & & \\
\hline Hemostasis & $\mathrm{X}$ & & & $\mathrm{X}$ & & & $\mathrm{X}$ & $\mathrm{X}$ & & \\
\hline Rheology & $\mathrm{X}$ & & & $\mathrm{X}$ & $\mathrm{X}$ & $\mathrm{X}$ & $\mathrm{X}$ & $\mathrm{X}$ & & \\
\hline Laboratory & $\mathrm{X}$ & & & $\mathrm{X}$ & & & $\mathrm{X}$ & $\mathrm{X}$ & & \\
\hline ESS & $\mathrm{X}$ & & & $\mathrm{X}$ & & & & $\mathrm{X}$ & $\mathrm{X}$ & $\mathrm{X}$ \\
\hline Barthel Index & $\mathrm{X}$ & & & & & & & & $\mathrm{X}$ & $\mathrm{X}$ \\
\hline Study drug administration & $\mathrm{X}^{1}$ & & & & & & & & & \\
\hline $\begin{array}{l}\text { Documentation of adverse events } \\
\text { (plus itching questionnaire on day 90) }\end{array}$ & & $\mathrm{X}$ & $\mathrm{X}$ & $\mathrm{X}$ & $\mathrm{X}$ & $\mathrm{X}$ & $\mathrm{X}$ & $\mathrm{X}$ & $\mathrm{X}$ & $\mathrm{X}$ \\
\hline
\end{tabular}

1 Study drug infusion was started only after completion of all other baseline investigations.

atinine, aspartate aminotransferase, alanine aminotransferase, gamma-glutamyltransferase, alpha-amylase, lipase) were measured at baseline and on days 1, 4 and 5. Rheological parameters (hematocrit and plasma viscosity) were measured at baseline and daily from day 1 to 5 .

Clinical Parameters. For all patients, the European Stroke Scale (ESS) and Barthel Index were determined at baseline, on days 1 and 5 and on the day of discharge. After 90 days, a telephone follow-up was carried out for the Barthel Index and the adverse event questionnaire, including possible pruritus.

\section{Statistical Analysis}

For the comparison of the treatment groups with respect to the target variable, statistical tests (t-test, covariance analysis) were used. The technique of last observation carried forward was used. No interim analysis was performed. Double data entry was performed into an SAS $^{\circledR}$ database and checked for validity. One-sided t-test was used for the treatment comparison with a significance level of alpha = 0.05 . Correlation analysis was carried out for the rheological parameters and hemodynamics and hemostasis, as well as for the Barthel Index and the ESS. The Wilcoxon rank-sum test was used for the ESS and Barthel Index to compare the treatment groups. Comparability of the two treatment groups was assessed by Fisher's exact test, Student's t-test, the Wilcoxon rank-sum test and Cochran-MantelHaenszel methodology. The sample size estimation was based on a significance level of alpha $=0.05$ and a power of $80 \%$.

Hydroxyethyl Starch Therapy for Acute

Ischemic Stroke

\section{Results}

\section{General Results}

There were no differences between the treatment groups in regard to demography and baseline characteristics considered likely to affect the results of the study. The time interval between the ischemic event and the start of the medication was comparable in both treatment groups. There were no relevant differences between the groups with respect to fever, infections and medication.

A total of 40 patients were enrolled. 20 were randomized into the HES group and 20 were randomized into the crystalloid solution group. All patients received 6,500 ml of study medication during the first 4 days. Acetylsalicylic acid (dosage $250 \mathrm{mg} /$ day p.o.) was the most frequently recorded concomitant medication $(85.0 \%$ of the patients in the HES group and $95.0 \%$ of the patients in the group receiving crystalloid solution), followed by electrolytic salts (calcium, potassium, sodium and magnesium acetate; $75.0 \%$ in the HES group vs. $80.0 \%$ in the group receiving crystalloid solution). Clopidogrel (dosage 75 $\mathrm{mg}$ /day p.o.) was recorded in $35.0 \%$ of the HES group versus $25.0 \%$ of the crystalloid solution group.

Pathophysiol Haemost Thromb 2003;33:121-126 
Table 2. Hematology, clinical chemistry, ESS and Barthel Index of the HES and electrolyte groups

\begin{tabular}{|c|c|c|c|c|c|c|c|c|}
\hline & \multicolumn{4}{|c|}{ HES group } & \multicolumn{4}{|c|}{ Electrolyte group } \\
\hline & \multicolumn{2}{|c|}{$\begin{array}{l}\text { baseline } \\
\text { examination }\end{array}$} & \multicolumn{2}{|c|}{$\begin{array}{l}\text { examination } \\
\text { after } 5 \text { days }\end{array}$} & \multicolumn{2}{|c|}{$\begin{array}{l}\text { baseline } \\
\text { examination }\end{array}$} & \multicolumn{2}{|c|}{$\begin{array}{l}\text { examination } \\
\text { after } 5 \text { days }\end{array}$} \\
\hline & mean & SD & mean & SD & mean & $\mathrm{SD}$ & mean & $\mathrm{SD}$ \\
\hline \multicolumn{9}{|l|}{ Hematology } \\
\hline Hemoglobin, g/dl & 14.44 & 1.4 & 13.37 & 1.2 & 14.9 & 1.29 & 13.87 & 1.39 \\
\hline Leukocytes, $\times 10^{6} / \mathrm{dl}$ & 8,825 & 2,638 & 8,121 & 2,227 & 8,085 & 2,035 & 7,974 & 1,724 \\
\hline \multicolumn{9}{|l|}{ Clinical chemistry } \\
\hline Glucose, mg/dl & 114.3 & 49.74 & 112 & 27.73 & 98.65 & 15.09 & 105.5 & 23.6 \\
\hline Creatinine, $\mathrm{mg} / \mathrm{dl}$ & 0.87 & 0.21 & 0.94 & 0.3 & 0.86 & 0.17 & 0.96 & 0.16 \\
\hline ASAT, U/l & 10.2 & 3.49 & 10.58 & 5.7 & 11.15 & 6.02 & 12.11 & 4.33 \\
\hline ALAT, U/1 & 12 & 6.49 & 13.21 & 9.93 & 14.5 & 13.24 & 18.42 & 11.09 \\
\hline$\gamma-\mathrm{GT}, \mathrm{U} / 1$ & 25.65 & 22.64 & 27.21 & 27.45 & 23.47 & 21.31 & 22.68 & 15.94 \\
\hline Alpha-amylase, U/l & 60.89 & 36.84 & 118.3 & 50.06 & 66.1 & 43 & 62.00 & 35.01 \\
\hline Lipase, U/1 & 61.88 & 54.57 & 73.21 & 69.64 & 59.26 & 43.9 & 71.82 & 43.71 \\
\hline ESS sum score & 92.74 & 10.71 & 95.39 & 8.84 & 93.15 & 6.53 & 96.6 & 5.99 \\
\hline Barthel Index & 91.05 & 19.33 & $97.63^{1}$ & $10.32^{1}$ & 94.5 & 16.85 & $99.5^{1}$ & $1.54^{1}$ \\
\hline
\end{tabular}

ASAT $=$ Aspartate aminotransferase; ALAT $=$ alanine aminotransferase; $\gamma$-GT = gamma-glutamyltransferase .

1 These data were obtained on the day of discharge.

Regarding the clinical outcome in this study, there was a positive tendency in both groups regarding the effect on the patients' condition, as shown by the ESS and the Barthel Index (table 2). In the electrolyte group, the baseline Barthel Index was 94.5 points. Therefore, the maximum improvement in this group was limited to 5.5 points. The increase in the mean sum score of the ESS was about $4.5 \%$ for both groups. With regard to the Barthel Index, the increase in the HES group was two times the increase in the reference group (on day 90). In all of these cases, the standard deviation was greater than the increase.

\section{Hemodynamics}

For cardiac output as the primary efficacy parameter in the study, an increase could be seen and maintained throughout the treatment period $(96 \mathrm{~h})$. This increase was about 0.5 liters $/ \mathrm{min}$. The mean systolic and diastolic blood pressure decreased in both treatment groups during the treatment (table 3). There was no significant difference between the two groups. However, additional medication was not ruled out, so that a potential influence on blood pressure is possible. Comparing the cerebral perfusion measured by TCD, the values for systolic, mean and diastolic flow velocity in the middle cerebral artery (TCD Vmax, Vmean and Vmin) for the affected and unaffected hemisphere showed no remarkable differences.

\section{Laboratory Parameters}

There were no statistically significant changes in the hematological, hemostaseological and clinical chemistry parameters in the two groups, with the exception of alpha-amylase, which increased significantly in the HES group ( $p=0.0001$, Wilcoxon test) (table 2$)$. The study treatment had no effect on rheological parameters measured in both groups. The small dilutional effects of continuous infusion were considered not to be clinically relevant.

\section{Adverse Events}

There were no relevant differences between the two treatment groups concerning the total number, the intensity and relationship of adverse events to the study medication. Itching was reported by 5 patients, i.e. 3 patients in the HES group and 2 patients in the crystalloid group. One serious adverse event (neuroborreliosis) occurred in the crystalloid group, but this was not related to the study medication.

Correlation analyses were performed for hemodynamic, rheology, hemostasis and outcome parameters. No strong correlation was found (all correlation coefficients $<0.72)$. 
Table 3. Rheological parameters of the HES and electrolyte groups

\begin{tabular}{|c|c|c|c|c|c|c|c|c|}
\hline & \multicolumn{4}{|c|}{ HES group } & \multicolumn{4}{|c|}{ Electrolyte group } \\
\hline & \multicolumn{2}{|c|}{$\begin{array}{l}\text { baseline } \\
\text { examination }\end{array}$} & \multicolumn{2}{|c|}{$\begin{array}{l}\text { examination } \\
\text { after } 96 \mathrm{~h}\end{array}$} & \multicolumn{2}{|c|}{$\begin{array}{l}\text { baseline } \\
\text { examination }\end{array}$} & \multicolumn{2}{|c|}{$\begin{array}{l}\text { examination } \\
\text { after } 96 \mathrm{~h}\end{array}$} \\
\hline & mean & $\mathrm{SD}$ & mean & SD & mean & $\mathrm{SD}$ & mean & SD \\
\hline \multicolumn{9}{|l|}{ Blood pressure, $\mathrm{mm} \mathrm{Hg}$} \\
\hline Systolic & 151.68 & 20.09 & 143.63 & 19.07 & 157.10 & 24.38 & 148.25 & 16.34 \\
\hline Diastolic & 86.05 & 12.72 & 81.53 & 10.38 & 86.9 & 13.13 & 81.75 & 11.13 \\
\hline Heart rate, beats/min & 75 & 19.72 & 73.39 & 8.23 & 69.7 & 11.72 & 68.75 & 9.41 \\
\hline Stroke volume, $\mathrm{ml} /$ beat & 73.01 & 26.14 & 77.36 & 20.2 & 77.89 & 24.42 & 91.51 & 30.05 \\
\hline Hematocrit, \% & 42.43 & 4.13 & 37.95 & 3.49 & 44.2 & 3.4 & 40.05 & 3.26 \\
\hline Plasma viscosity, $\mathrm{mPa}$ & 1.08 & 0.08 & 1.08 & 0.08 & 1.07 & 0.06 & 1.04 & 0.05 \\
\hline
\end{tabular}

\section{Discussion}

Hypervolemic hemodilution attempts to optimize cerebral perfusion of ischemic regions through an optimization of rheological parameters and an increase in cardiac output and blood pressure [2, 3, 8,9]. Administration of volume optimizes ventricular filling and increases cardiac output via an increase in cardiac stroke volume without an increase in heart rate. Several studies support the clinical efficacy of this concept, albeit with limitations $[6,7,9$, 10]. A recently published multicenter study confirmed the safety of hypervolemic hemodilution; however, the small patient groups did not allow for clinical efficacy to be shown statistically [6].

Our study showed that a continuous hypervolemic volume therapy with HES 130/0.4, despite a large cumulative dose of 6.5 liters over 4 days, does not result in improved systemic or cerebral perfusion compared to crystalloid solution. Since hematocrit was not changed significantly, the reason is probably that the volume effect of a continuous infusion (about $1 \mathrm{ml} / \mathrm{min}$ ) is too small. Repeated, short-term infusions in a more pulsatile fashion might result in a more positive effect. This point was the subject of a recent multicenter study [17]. In that study, high-dose hypervolemic hemodilution with HES or $\mathrm{NaCl}$ was generally safe and well tolerated, and there was a nonsignificant trend towards a better functional outcome with HES therapy [17]. At the time of baseline examination in the present study, the patients in the HES group as well as those in the electrolyte group exhibited a mean Barthel score of $>90$ points. Thus, the majority of our patients had only minor neurological signs. So, the results of our study are not necessarily comparable with those in patients with severe neurological deficits.
Our study, which was developed particularly under the aspect of therapeutic safety, shows that the newly developed 6\% HES 130/0.4 is a safe drug. The side effects are comparable to those with crystalloid solution. $6 \%$ HES $130 / 0.4$, which is newly designed and was only recently approved for use in Europe, is also safe when used for a long-term, high-dose volume therapy. Particularly regarding bleeding complications, which are a much feared side effect of hetastarch, the present study was able to show that $6 \%$ HES 130/0.4 leads to no measurable effect on the coagulation system in general or factor VIII/von Willebrand factor in particular when compared to crystalloid solution. This holds true for a total dose of $6,500 \mathrm{ml}$ infused over 4 days.

Due to the pharmacological properties of the new HES $130 / 0.4$, this was an expected outcome, because the initial molecular weight and molar substitution are low, resulting in a low in vivo molecular weight still above the renal threshold. Earlier studies [18-20] showed that even repeated administration leads to no plasma accumulation, due to the low molar substitution of 0.4 and good renal elimination, while the volume effect and hemodynamic effects are preserved compared to HES 200/0.5 [21].

The favorable elimination kinetics of HES 130/0.4 leads to a lesser storage of starch molecules in the reticuloendothelial system (RES) than older starches with a higher molar substitution. This has already been shown in animal studies [22]. This decreased storage in the RES is supported by the fact that the fibronectin concentration is not affected by HES 130/0.4. In an earlier study with HES $200 / 0.62$, which is difficult to metabolize, a $50 \%$ decrease of fibronectin was observed [2].

One important side effect of high cumulative HES doses is itching. In the past, the occurrence of a therapy- 
resistant pruritus after a high-dose, long-term infusion of HES has been described repeatedly. This pruritus is thought to be associated with storage of HES in the RES and occurs in general only after infusing a total dose larger than $300 \mathrm{~g}$ [23]. The reduced storage of HES 130/0.4 due to a more rapid renal elimination explains why pruritus in the HES group did not occur significantly more often than in the crystalloid group, despite the large volume infused.

The only laboratory parameter significantly affected by HES 130/0.4 was alpha-amylase. The significant increase in alpha-amylase is well known because of the formation of macroamylase, and is not a sign of pancreatic impairment. This is also confirmed by the unchanged lipase concentration. These effects have been observed frequently in the past. Treib [2] reported a five-fold increase in serum amylase after a long-term infusion of HES 200/0.62, a starch which is difficult to break down.

In summary, HES 130/0.4, even when infused in large quantities, has a high degree of therapeutic safety which does not differ significantly from crystalloid solution in the infusion model used. However, HES 130/0.4 was not superior to crystalloid solution regarding the therapeutic effect on systemic and cerebral perfusion during continuous infusion.

\section{Acknowledgements}

We would like to thank Dr. Frank Zippel, Nicole Stock, Sonja Kaftan and Frank Grieger (IFE Europe GmbH) for the statistical analysis.

This study was funded by Fresenius Kabi Germany. Fresenius Kabi took over the costs for study medication, data assessment, statistical analysis, patient insurance and the ethics committee and contributed to the research fund of our clinic. The research fund is controlled by our administration, so that there are no personal financial advantages for the researchers.

All authors had full access to the primary data. The sponsor did not influence the data analysis.

\section{References}

1 Baron J-F, Treib J (eds): Volume Replacement. Berlin, Springer, 1998

2 Treib J (ed): Volume Therapy. Berlin, Springer, 2000

3 Treib J, Grauer MT, Woessner R, Morgenthaler M: Treatment of stroke on an intensive stroke unit: A novel concept. Intensive Care Med 2000;26:1598-1611.

4 Mast H, Marx P: Neurological deterioration under isovolemic hemodilution with hydroxyethyl starch in acute cerebral ischemia. Stroke 1991:22:680-683.

5 Haemodilution in acute stroke: Results of the Italian haemodilution trial. Italian Acute Stroke Study Group. Lancet 1988;i:318-321.

6 Aichner FT, Fazekas F, Brainin M, Polz W, Mamoli B, Zeiler K: Hypervolemic hemodilution in acute ischemic stroke: The Multicenter Austrian Hemodilution Stroke Trial (MAHST). Stroke 1998;29:743-749.

7 Koller M, Haenny P, Hess K, Weniger D, Zangger P: Adjusted hypervolemic hemodilution in acute ischemic stroke. Stroke 1990;21: 1429-1434.

8 Strand T: Evaluation of long-term outcome and safety after hemodilution therapy in acute ischemic stroke. Stroke 1992;23:657-662.

9 Strand T, Asplund K, Eriksson S, Hägg E, Lithner F, Wester PO: A randomized controlled trial of hemodilution therapy in acute ischemic stroke. Stroke 1984;15:980-989.

10 Hypervolemic hemodilution treatment of acute stroke. Results of a randomized multicenter trial using pentastarch. The Hemodilution in Stroke Study Group. Stroke 1989;20: 317-323.
11 Kaplan S, Park TS, Gonzales E, Gidday J: Hydroxyethyl starch reduces leukocyte adherence and vascular injury in the newborn pig cerebral circulation after asphyxia. Stroke 2000; 31:2218-2223.

12 Treib J, Baron JF, Grauer MT, Strauss RG: An international view of hydroxyethyl starches. Intensive Care Med 1999;25:258-268.

13 Treib J, Haass A, Pindur G: Coagulation disorders caused by hydroxyethyl starch. Thromb Haemost 1997;78:974-983.

14 Treib J, Haass A, Pindur G, Grauer MT, Wenzel E, Schimrigk K: All medium starches are not the same: Influence of the degree of hydroxyethyl substitution of hydroxyethyl starch on plasma volume, hemorrheologic conditions and coagulation. Transfusion 1996;36:450455.

15 Treib J, Haass A, Pindur G, Seyfert UT, Treib W, Grauer MT, Jung F, Wenzel E, Schimrigk K: HES 200/0.5 is not HES 200/0.5. Influence of the C2/C6 hydroxyethylation ratio of hydroxyethyl starch (HES) on hemorheology, coagulation and elimination kinetics. Thromb Haemost 1995;74:1452-1456.

16 Treib J, Haass A, Krammer I, Stoll M, Grauer MT, Schimrigk K: Cardiac output in patients with acute stroke. J Neurol 1996;243:575-578.

17 Rudolf J: Hydroxyethyl starch for hypervolemic hemodilution in patients with acute ischemic stroke: A randomized, placebo-controlled phase II safety study. Cerebrovasc Dis 2002;14: 33-41.
18 Waitzinger J, Bepperling F, Pabst G, Opitz J, Müller M, Baron JF: Pharmacokinetics and tolerability of a new hydroxyethyl starch (HES) specification (HES 130/0.4) after single-dose infusion of $6 \%$ or $10 \%$ solutions in healthy volunteers. Clin Drug Invest 1998;16:151-160.

19 Waitzinger J, Bepperling F, Pabst G, Opitz J, Fackelmeyer A, Boldt J: Effect of a new hydroxyethyl starch (HES) specification $(6 \%$ HES $130 / 0.4$ ) on blood and plasma volumes after bleeding in 12 healthy male volunteers. Clin Drug Invest 1999;17:119-125.

20 Waitzinger J, Bepperling F, Pabst G, Opitz J: Hydroxyethyl starch (HES) [130/0.4], a new HES specification: Pharmacokinetics and safety after multiple infusions of $10 \%$ solution in healthy volunteers. Drug R D 2003;4:149157.

21 Langeron O, Doelberg M, Ang ET, Bonnet F, Capdevila X, Coriat P: Voluven, a lower substituted novel hydroxyethyl starch (HES 130/0.4), causes fewer effects on coagulation in major orthopedic surgery than HES 200/0.5. Anesth Analg 2001;92:855-862

22 Leuschner J, Opitz J, Winkler A, Scharpf R, Bepperling F: Tissue storage of ${ }^{14} \mathrm{C}$-labelled hydroxyethyl starch (HES 130/0.4) and HES 200/0.5 after repeated intravenous administration to rats. Drugs R D 2003;4:331-338.

23 Gröchenig E, Albegger K, Dieterich HJ, et al: Hydroxyethylstarch-related pruritus: A prospective multicenter investigation of 544 patients. Perfusion 1998;11:62-69. 